\title{
A complementarity model and algorithm for supply chain with immediate marketing order
}

\author{
Guirong Pan ${ }^{\mathrm{a}, *}$, Haodong Chen ${ }^{\mathrm{b}, *}$, Hongchun Sun ${ }^{\mathrm{b}, *}$ \\ a School of Information Science and Engineering, Linyi University, Linyi, Shandong, 276005, China. \\ ${ }^{b}$ School of Mathematics and Statistics, Linyi University, Linyi, Shandong, 276005, China.
}

\begin{abstract}
Based on the research of supply chain management, a complementary model of supply chain with immediate marketing order single commodity is established. In order to give the optimal decision of the problem, a new-type algorithm is presented in this paper to obtain the solution of the model. The rationality of the model and the effectiveness of the algorithm are illustrated by an example.
\end{abstract}

Keywords: Immediate marketing, single commodity, complementarity model, algorithm.

2010 MSC: 90С30, 90C33, 90B06.

(C)2020 All rights reserved.

\section{Introduction}

Due to the rapid development of the economy and the improvement of people's living standards, the research on supply chain management has attracted extensive research from scholars at home and abroad. Supply chain is a coordinated system composed of manufacturers, retailers, and consumer markets. In this system, under the guarantee of the interests of all aspects, they cooperate with each other and influence each other. It's goal is to maximize the overall interests. Therefore, the supply chain management plays an important role in logistics and transportation. It adjusts the members of the supply chain to maintain the stable development of the chain. In recent years, both in the application and academic research, supply chain management has been becoming a hot topic of modern logistics research, and so provoked strong research interest of many scholars. The research area involves the model, analysis and computation for supply chain management, related to manufacturing, transportation, logistics, retail, and sales [5-7]. Zhang and Dong [11] presented a new framework for supply chain, using graph theory, optimization theory, and variational inequality theory. It develops a general network model of a supply chain economy to study supply chain versus supply chain competition. Zhan [10] reformulates the supply

\footnotetext{
*Corresponding authors

Email addresses: panguirong@lyu.edu.cn (Guirong Pan), 2101058556@qq.com (Haodong Chen), sunhongchun@sina.com (Hongchun Sun)
}

doi: $10.22436 /$ jmcs.020.01.06

Received: 2019-07-02 Revised: 2019-07-28 Accepted: 2019-08-01 
chain problem as a nonlinear complementarity model, give weaker conditions to guarantee the existence and uniqueness of an equilibrium pattern. Nagurney et al. [4] developed a supply chain model in which both physical and electronic transactions are allowed and in which supply side risk as well as demand side risk are included in the formulation. Malitsky [3] is concerned with some new projection methods for solving variational inequality problems with monotone and Lipschitz-continuous mapping in Hilbert space. Zhang and Sun [12] studied a closed-loop supply chain problem in multiperiod planning horizons with consideration of product lifetime and carbon emission constraints. Fu and Chen [1] studied multiobjective decision-making optimization, which focuses on equilibrium and compensation of multiobjective problems. In this paper, according to the current problems of supply chain management, we set up an immediate marketing single commodity supply chain model, and through a new-type algorithm, obtain the solution of the supply chain model. The article finally uses numerical examples to demonstrate the validity of the model through experiment and the feasibility of the algorithm.

\section{The complementarity model for the supply chain}

The supply chain is mainly composed of three parts: product manufacturer, retailer, and consumer market. This paper describes the decision-making of the members of the three-tier competitive market of the supply chain, and is shown in Figure 1 below. The complementary model of the supply chain with immediate marketing orders single commodity is established.

Because of the research needs, let's say $m$ manufacturers produce homogeneous products, and these products are supplied to $n$ retailers. Accordingly, retailers provide products for o desired markets. Here, " $i$ " for the $i$-th manufacturer, " $j$ " for the $j$-th retailer, and " $k$ " for the $k$-th demand market.

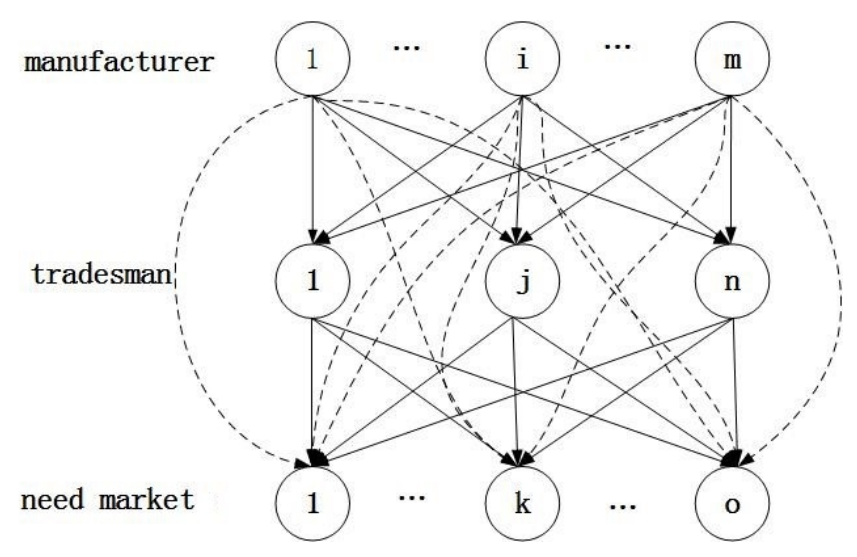

Figure 1: Structure of the supply chain with immediate marketing orders single commodity.

\subsection{Competition model of manufacturer}

Let $\mathrm{q}_{i j}$ represents the volume of goods transported by manufacturer $i$ to retailer $j$, and $Q^{11}$ represents $m n$ dimension column vectors composed of all $q_{i j}$, namely,

$$
\mathrm{Q}^{11}=\left(\mathrm{q}_{11}, \ldots, \mathrm{q}_{1 \mathrm{n}}, \ldots, \mathrm{q}_{\mathrm{m} 1}, \ldots, \mathrm{q}_{\mathrm{mn}}\right)^{\mathrm{T}} .
$$

Let $q_{i k}$ represents the traffic volume of manufacturer $i$ selling products directly to the consumer market $k$, and $Q^{12}$ represents mo dimension vector composed of all $q_{i k}$, namely,

$$
Q^{12}=\left(q_{11}, \ldots, q_{10}, \ldots, q_{m 1}, \ldots, q_{m o}\right)^{\top}
$$

For the convenience of the following expression, the manufacturer's traffic volume is expressed as $\mathrm{Q}^{1}=$ $\left(\mathrm{Q}^{11}, \mathrm{Q}^{12}\right)$. 
Assuming that each manufacturer $i$ corresponds to a production cost function $f_{i}$, the entire vector of production output can be expressed as

$$
f_{i}=f_{i}\left(Q^{1}\right) .
$$

Let $c_{i j}$ represents the transaction cost (including transportation cost) of a product traded between manufacturer $i$ and retailer $j$, taking into account the transaction cost between manufacturer and all retailers and recording it as

$$
c_{i j}=c_{i j}\left(q_{i j}\right), \forall i, j .
$$

Let $c_{i k}$ represents the transaction cost (including transportation cost) of a product traded between manufacturer $i$ and consumer market $k$, taking into account the transaction cost between manufacturer and all consumer markets and recording it as

$$
c_{i k}=c_{i k}\left(q_{i k}\right), \forall i, k .
$$

For the convenience of the following description, all transaction costs of the manufacturer are expressed as $c_{i}=\left(c_{i j}, c_{i k}\right)$. Let $\rho_{1 i j}$ denote the price of manufacturer $i$ sell to the vendor $j, \rho_{1 i k}$ denote the price of manufacturer $i$ sell to the consumer marker $k$.

For manufacturers, the purpose of production is to maximize their profits in competition. Manufacturers usually need to make decisions on the production quantity and supply plan of products. Therefore, the market behavior of any manufacturer $i$ can be described by the following optimization model:

$$
\begin{gathered}
\max \sum_{j=1}^{n} \rho_{1 i j} q_{i j}+\sum_{k=1}^{o} \rho_{1 i k} q_{i k}-f_{i}\left(Q^{11}, Q^{12}\right)-\sum_{j=1}^{n} c_{i j}\left(q_{i j}\right)-\sum_{k=1}^{o} c_{i k}\left(q_{i k}\right), \\
\text { s.t. } \quad q_{i j} \geqslant 0, q_{i k} \geqslant 0, i=1,2, \ldots, m ; j=1,2, \ldots, n ; k=1,2, \ldots, o .
\end{gathered}
$$

Suppose that the competitions of manufacturers are non-cooperative, the production cost functions $f_{i}$ and the transaction cost functions are $c_{i}$ continuously differentiable convex functions then, the optimization problem (2.1) is a convex programming. Assume that $\mathrm{Q}^{1}=\left(\mathrm{Q}^{11}, \mathrm{Q}^{12}\right)$ is the optimal solution of (2.1), then, $\mathrm{Q}^{1}$ is a "equilibrium solution" of manufacturer, and satisfies the following KKT condition:

$$
\left\{\begin{array}{c}
\nabla f_{i}\left(Q^{11}, Q^{12}\right)+\sum_{j=1}^{n} \nabla c_{i j}\left(q_{i j}\right)+\sum_{k=1}^{o} \nabla c_{i k}\left(q_{i k}\right)-\Sigma_{j=1}^{n} \rho_{1 i j} e_{j}-\Sigma_{k=1}^{o} \rho_{1 i k} e_{k} \\
\quad=\left(\lambda_{i 1}, \ldots, \lambda_{i n}, \lambda_{i(n+1)}, \ldots, \lambda_{i(n+o)}\right)^{\top} \geqslant 0, \\
q_{i j} \geqslant 0, q_{i k} \geqslant 0, \lambda_{i j} q_{i j}=0, \lambda_{i k} q_{i k}=0, j=1,2, \ldots, n, k=1,2, \ldots, o,
\end{array}\right.
$$

where $\lambda_{i}=\left(\lambda_{i j}, \lambda_{i k}\right)$ is Lagrange multiplier, $e=\left(e_{i}, e_{j}\right)$ is unit vector, $i$ ts $i$-th and $j$-th component is 1 , and the other components are 0. Formula (2.2) is equivalent to

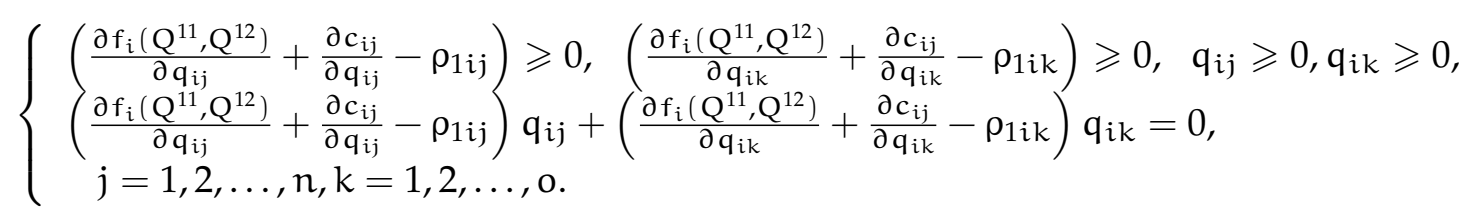

For the convenience of the following description, the (2.3) is abbreviated as

$$
f\left(w_{1}\right) \geqslant 0, \quad w_{1} \geqslant 0, \quad w_{1}^{\top} f\left(w_{1}\right)=0,
$$

where

$$
f\left(w_{1}\right)=\left(\begin{array}{c}
\frac{\partial f_{i}\left(Q^{11}, Q^{12}\right)}{\partial q_{i j}}+\frac{\partial c_{i j}}{\partial q_{i j}}-\rho_{1 i j} \\
\frac{\partial f_{i}\left(Q^{11}, Q^{12}\right)}{\partial q_{i k}}+\frac{\partial c_{i j}}{\partial q_{i k}}-\rho_{1 i k} \\
i=1,2, \ldots, m \\
j=1,2, \ldots, n \\
k=1,2, \ldots, 0
\end{array}\right), \quad w_{1}=\left(\begin{array}{c}
q_{i j} \\
q_{i k} \\
i=1,2, \ldots, m \\
j=1,2, \ldots, n \\
k=1,2, \ldots, o
\end{array}\right) .
$$




\subsection{Competition model of retailers}

Retailers trade with manufacturers because they want to get their products from them to meet inventory needs. At the same time, they have to trade with the customers who want the market, because their final products have to be sold to the consumers. The network structure diagram of its $j$ retailer trading products with manufacturers and demand markets is shown in Figure 2.

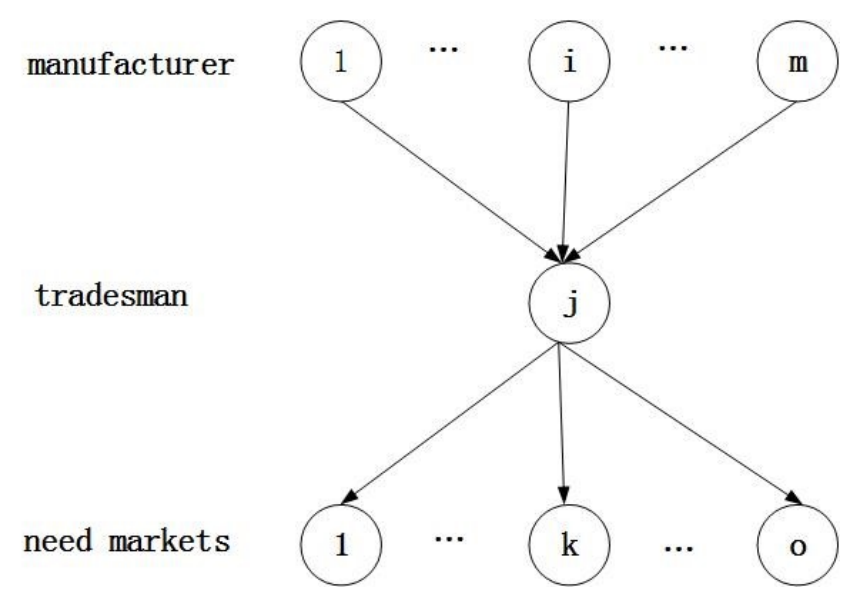

Figure 2: The trade network structure of the J retailer.

Retailer $j$ has to face the management cost in the network, for example, it may include the cost of product exhibition and storage, etc., $c_{j}$ is the management cost of the $j$ tradesman, and the simplest form is to think of $c_{j}$ as a function of $\sum_{i=1}^{m} q_{i j}$. However, in order to improve the competitiveness of the model, the management cost of retailer $j$ also depends on the purchase quantity of other retailers in general. Therefore, $c_{j}$ can be expressed as

$$
c_{j}=c_{j}\left(Q^{11}\right), \forall j,
$$

$\rho_{j k}$ represents the price that retailer $j$ sells to demand market $k$. Then the optimization problem of retailer $j$ can be described as follows:

$$
\max \sum_{k=1}^{o} \rho_{j k} q_{i j}-c_{j}\left(Q^{11}\right)-\sum_{i=1}^{m} \rho_{1 i j} q_{i j}, \quad \text { s.t. } \quad q_{i j} \geqslant 0, i=1,2, \ldots, m .
$$

The optimization problem (2.5) is a convex programming, according to optimization theory, and (2.5) satisfies the following KKT condition:

$$
\left\{\begin{array}{l}
\nabla c_{j}\left(Q^{11}\right)+\sum_{i=1}^{m} \nabla \rho_{1 i j}\left(q_{i j}\right)-\sum_{k=1}^{o} \rho_{j k} e_{k}=\left(\lambda_{i 1}, \ldots, \lambda_{i o}\right)^{\top} \geqslant 0, \\
q_{i j} \geqslant 0, \lambda_{i k} q_{i j}=0, k=1,2, \ldots, o,
\end{array}\right.
$$

where $\lambda_{i k}$ is Lagrange multiplier, $e_{k}$ is unit vector, its $k$-th component is 1 , and the other components are 0 . Formula (2.6) is equivalent to

$$
\left\{\begin{array}{l}
\frac{\partial c_{j}\left(Q^{11}\right)}{\partial q_{j}}+\frac{\partial \rho_{1 i j}\left(q_{i j}\right)}{\partial q_{i j}}-\rho_{j k} \geqslant 0, q_{i j} \geqslant 0, j=1,2, \ldots, n, \\
\left(\frac{\partial c_{j}\left(Q^{11}\right)}{\partial q_{j}}+\frac{\partial \rho_{1 i j}\left(q_{i j}\right)}{\partial q_{i j}}-\rho_{j k}\right) q_{i j}=0, j=1,2, \ldots, n .
\end{array}\right.
$$

For the convenience of the following description, the (2.7) is abbreviated as

$$
g\left(w_{2}\right) \geqslant 0, w_{2} \geqslant 0, w_{2}^{\top} g\left(w_{2}\right)=0,
$$

where

$$
g\left(w_{2}\right)=\frac{\partial c_{j}\left(Q^{11}\right)}{\partial q_{j}}+\frac{\partial \rho_{1 i j}\left(q_{i j}\right)}{\partial q_{i j}}-\rho_{j k}, w_{2}=q_{i j} .
$$

Based on the above (2.4) and (2.8), it can be concluded that the network equilibrium model with 
immediate marketing single commodity is:

$$
x \geqslant 0, F(x) \geqslant 0, x^{\top} F(x)=0,
$$

where $x=\left(\begin{array}{l}w_{1} \\ w_{2}\end{array}\right), F(x)=\left(\begin{array}{l}f\left(w_{1}\right) \\ g\left(w_{2}\right)\end{array}\right)$. We use $X^{*}$ to denote the solution set of (2.9), and assume that $X^{*}$ is not empty.

\section{Algorithm}

In this section, we would give a new-type method solving (2.9), we first need some relate properties.

Definition 3.1 ([2]). A mapping $F: \mathbb{R}^{n} \rightarrow \mathbb{R}^{n}$ is called monotone on the set $C$ if for any $x, y \in C$, one has $\langle F(x)-F(y), x-y\rangle \geqslant 0$ holds.

We also give the definition of projection operator and some related properties $([2,8,9])$.

Definition 3.2. For a nonempty closed convex set $\Omega \in \mathbb{R}^{n}$ and vector $x \in \mathbb{R}^{n}$, the orthogonal projection of $x$ onto $\Omega$, i.e., $\operatorname{argmin}\{\|y-x\| \mid y \in \Omega\}$, is denoted by $\mathrm{P}_{\Omega}(x)$.

Lemma 3.3. Suppose that $\Omega$ be a closed convex subset of $\mathbb{R}^{\mathrm{n}}$. Then we have the following statements hold

(i) $z=\mathrm{P}_{\Omega}(\mathrm{x}) \Leftrightarrow z \in \Omega$ and $\langle z-x, y-z\rangle \geqslant 0, \forall y \in \Omega$;

(ii) $\left\|P_{\Omega}(x)-P_{\Omega}(y)\right\| \leqslant\|x-y\|, \forall x, y \in \mathbb{R}^{n}$;

(iii) $\left\|P_{\Omega}(x)-x\right\|^{2} \leqslant\|x-y\|^{2}-\left\|P_{\Omega}(x)-y\right\|^{2}, \forall x \in \mathbb{R}^{n}, \forall y \in \Omega$.

For (2.9), we define the projection residue $e(x, \lambda):=\min \{x, \lambda F(x)\}$ and $r(x, \lambda):=\|e(x, \lambda)\|$, where $\lambda>0$.

Lemma 3.4 ([8]). $x$ is a solution of (2.9) if and only if $r(x, \lambda)=0, \lambda>0$.

\section{Algorithm 3.5.}

Step 1: Select the initial point $x^{0} \in \mathbb{R}^{n}$, and $\lambda>0$. Let $k=0$.

Step 2: Compute

$$
y^{k}=\max \left\{0, x^{k}-\lambda F\left(x^{k}\right)\right\}
$$

If $r\left(x^{k}, \lambda\right)=0$, stop; otherwise, go to Step 3 .

Step 3: Compute

$$
x^{k+1}=P_{T_{k}}\left(x^{k}-\lambda d\left(x^{k}, \lambda\right)\right),
$$

where $T_{k}:=\left\{w \in \mathbb{R}^{n} \mid\left\langle x^{k}-\lambda F\left(x^{k}\right)-y^{k}, w-y^{k}\right\rangle \leqslant 0\right\}, d\left(x^{k}, \lambda\right):=\frac{1}{\lambda}\left(x^{k}-y^{k}\right)-\left(F\left(x^{k}\right)-F\left(y^{k}\right)\right)$ is a new direction.

Step 4: Let $k:=k+1$, go to step 2 .

Remark 3.6. We can obtain that $R_{+}^{n} \subseteq T_{k}$. In fact, for any $\xi \in R_{+}^{n} \backslash T_{k}$, using Lemma 3.3 (i) with $x:=$ $x^{k}-\lambda F\left(x^{k}\right), y^{k}=P_{R_{+}^{n}}\left(x^{k}-\lambda F\left(x^{k}\right)\right)$, one has

$$
\left\langle x^{k}-\lambda F\left(x^{k}\right)-y^{k}, \xi-y^{k}\right\rangle \leqslant 0 .
$$

Thus, we obtain $\xi \in T_{k}$. In addition $X^{*} \subseteq R_{+}^{n} \subseteq T_{k}$.

In the following, we discuss the convergence of Algorithm 3.5. To this end, we present the following assumption, which will be needed in the sequel.

\section{Assumption 3.7.}

(1) F is Lipschitz continuous with constant $L>0$; 
(2) $F$ is monotone on the set $R_{+}^{n}$.

Lemma 3.8. Suppose that Assumption 3.7 hold, and Algorithm 3.5 generates an infinite sequence $\left\{x^{k}\right\}$. Then, one has

$$
r\left(x^{k}, \lambda\right)^{2} \leqslant\left(1-\lambda^{2} L^{2}\right)^{-1}\left\{\left\|x^{k}-x^{*}\right\|^{2}-\left\|x^{k+1}-x^{*}\right\|^{2}\right\}, \quad \forall x^{*} \in X^{*} .
$$

Proof. Applying Assumption 3.7 (2) and (2.9), one has

$$
\left\langle\mathrm{F}(z), z-x^{*}\right\rangle^{\top} \geqslant 0, \forall z \geqslant 0, \forall x^{*} \in X^{*} .
$$

Assume $y=P_{R_{+}^{n}}(x-\lambda F(x))$, by Lemma $3.3(i)$, we obtain

$$
\left\langle x-\lambda F(x)-y, y-x^{*}\right\rangle \geqslant 0, \forall x^{*} \geqslant 0, \forall x \in \mathbb{R}^{n} .
$$

Since $y \geqslant 0$ and $X^{*} \subset T_{k}$. Substituting $z$ in (3.1) with $y$, combining this with (3.2), we get

$$
\left\langle\frac{1}{\lambda}(x-y)-(F(x)-F(y)), y-x^{*}\right\rangle \geqslant 0, \forall \lambda>0, \forall x^{*} \geqslant 0
$$

Since $X^{*} \subseteq R_{+}^{n} \subseteq T_{k}$, we obtain

$$
\begin{aligned}
\left\|x^{k+1}-x^{*}\right\|= & \left\|P_{\mathrm{T}_{k}}\left(x^{k}-\lambda d\left(x^{k}, \lambda\right)\right)-x^{*}\right\|^{2} \\
\leqslant & \left\|x^{k}-\lambda d\left(x^{k}, \lambda\right)-x^{*}\right\|^{2}-\left\|x^{k+1}-\left(x^{k}-\lambda d\left(x^{k}, \lambda\right)\right)\right\|^{2} \\
= & \left\|x^{k}-x^{*}\right\|^{2}-2 \lambda\left\langle x^{k}-x^{*}, d\left(x^{k}, \lambda\right)\right\rangle+\lambda^{2}\left\|d\left(x^{k}, \lambda\right)\right\|^{2} \\
- & \left(\left\|x^{k}-x^{k+1}\right\|^{2}-2 \lambda\left\langle x^{k}-x^{k+1}, d\left(x^{k}, \lambda\right)\right\rangle+\lambda^{2}\left\|d\left(x^{k}, \lambda\right)\right\|^{2}\right) \\
= & \left\|x^{k}-x^{*}\right\|^{2}-2 \lambda\left\langle x^{k+1}-x^{*}, d\left(x^{k}, \lambda\right)\right\rangle-\left\|x^{k}-x^{k+1}\right\|^{2} \\
= & \left\|x^{k}-x^{*}\right\|^{2}-2 \lambda\left\langle x^{k+1}-y^{k}, d\left(x^{k}, \lambda\right)\right\rangle-2 \lambda\left\langle y^{k}-x^{*}, d\left(x^{k}, \lambda\right)\right\rangle-\left\|x^{k}-x^{k+1}\right\|^{2} \\
= & \left\|x^{k}-x^{*}\right\|^{2}-2 \lambda\left\langle x^{k+1}-y^{k}, d\left(x^{k}, \lambda\right)\right\rangle-2 \lambda\left\langle y^{k}-x^{*}, \frac{1}{\lambda}\left(x^{k}-y^{k}\right)-\left(F\left(x^{k}\right)-F\left(y^{k}\right)\right)\right\rangle \\
& -\left\|x^{k}-x^{k+1}\right\|^{2} \\
\leqslant & \left\|x^{k}-x^{*}\right\|^{2}-2 \lambda\left\langle x^{k+1}-y^{k}, d\left(x^{k}, \lambda\right)\right\rangle-\left\|x^{k}-x^{k+1}\right\|^{2} \\
= & \left\|x^{k}-x^{*}\right\|^{2}-\left\|x^{k}-y^{k}+y^{k}-x^{k+1}\right\|^{2}-2 \lambda\left\langle x^{k+1}-y^{k}, \frac{1}{\lambda}\left(x^{k}-y^{k}\right)-\left(F\left(x^{k}\right)-F\left(y^{k}\right)\right)\right\rangle \\
= & \left\|x^{k}-x^{*}\right\|^{2}-\left\|x^{k}-y^{k}\right\|^{2}-\left\|y^{k}-x^{k+1}\right\|^{2}-2\left\langle x^{k}-y^{k}, y^{k}-x^{k+1}\right\rangle \\
& -2\left\langle x^{k+1}-y^{k}, x^{k}-y^{k}\right\rangle+2 \lambda\left\langle x^{k+1}-y^{k},\left(F\left(x^{k}\right)-F\left(y^{k}\right)\right)\right\rangle \\
= & \left\|x^{k}-x^{*}\right\|^{2}-\left\|x^{k}-y^{k}\right\|^{2}+\left\|\lambda\left(F\left(x^{k}\right)-F\left(y^{k}\right)\right)\right\|^{2} \\
& -\left\|y^{k}-x^{k+1}\right\|^{2}+2\left\langle x^{k+1}-y^{k}, \lambda\left(F\left(x^{k}\right)-F\left(y^{k}\right)\right)\right\rangle-\left\|\lambda\left(F\left(x^{k}\right)-F\left(y^{k}\right)\right)\right\|^{2} \\
= & \left\|x^{k}-x^{*}\right\|^{2}-\left\|x^{k}-y^{k}\right\|^{2}+\lambda^{2}\left\|\left(F\left(x^{k}\right)-F\left(y^{k}\right)\right)\right\|^{2}-\left\|y^{k}-x^{k+1}+\lambda\left(F\left(x^{k}\right)-F\left(y^{k}\right)\right)\right\|^{2} \\
\leqslant & \left\|x^{k}-x^{*}\right\|^{2}-\left\|x^{k}-y^{k}\right\|^{2}+\lambda^{2}\left\|\left(F\left(x^{k}\right)-F\left(y^{k}\right)\right)\right\|^{2} \\
\leqslant & \left\|x^{k}-x^{*}\right\|^{2}-\left(1-\lambda^{2} L\right)\left\|x^{k}-y^{k}\right\|^{2},
\end{aligned}
$$

where the first equality is by the definition of $x^{k+1}$, the first inequality follows from Lemma 3.3 (iii), the fifth equality is by (3.3), and the last inequality follows from Assumption 3.7 (2), then the desired result follows.

Theorem 3.9. Suppose that Assumption 3.7 holds, and $0<\lambda<\frac{1}{\mathrm{~L}},\left\{\mathrm{x}^{\mathrm{k}}\right\}$ be an infinite sequence generated by Algorithm 3.5. Then, the sequence $\left\{x^{k}\right\}$ converges to a solution of (2.9).

Proof. Let $x^{*} \in X^{*}$. From Lemma 3.8, one has $\left\|x^{k+1}-x^{*}\right\| \leqslant\left\|x^{k}-x^{*}\right\|$, i.e., the sequence $\left\{\left\|x^{k}-x^{*}\right\|\right\}$ is 
non-increasing and bounded. Thus, it converges, and one has

$$
\left(1-\lambda^{2} L^{2}\right) \sum_{k=0}^{\infty} r\left(x^{k}, \lambda\right)^{2} \leqslant\left\|x^{0}-x^{*}\right\|^{2} .
$$

Thus, we obtain

$$
\lim _{k \rightarrow \infty} r\left(x^{k}, \lambda\right)=0
$$

Simultaneously, we also obtain that the sequence $\left\{x^{k}\right\}$ is bounded. Therefore, there exists a convergent subsequence $\left\{x^{k_{i}}\right\}$ of $\left\{x^{k}\right\}$, denote its limit by $\bar{x}$, and $\bar{x} \geqslant 0$, by Step 2 of Algorithm 3.5, one has

$$
\lim _{i \rightarrow \infty} y^{k_{i}}=\bar{x} .
$$

Since $F(\cdot)$ and $\max (\cdot)$ are continuous, we have

$$
\bar{x}=\lim _{i \rightarrow \infty} y^{k_{i}}=\lim _{i \rightarrow \infty} \max \left\{0, x^{k_{i}}-\lambda F\left(x^{k_{i}}\right)\right\}=\max \{0, \bar{x}-\lambda F(\bar{x})\} .
$$

Applying Lemma 3.4, one has $\bar{x} \in X^{*}$. We can take $x^{*}=\bar{\chi}$ in the preceding arguments of Lemma 3.8. Thus the sequence $\left\{\left\|x^{k}-\bar{x}\right\|\right\}$ converges. Since $\bar{x}$ is limit point of the subsequence $\left\{x^{k_{i}}\right\}$, it easily follows that $\left\{\left\|x^{k_{i}}-\bar{x}\right\|\right\}$ converges to zero, we have $\left\{\left\|x^{k}-\bar{x}\right\|\right\}$ converges to zero, i.e., $x^{k}$ converges to $\bar{x}$. Thus, the global convergence can be obtained.

\section{Numerical example}

In order to obtain the network equilibrium conditions of direct selling single commodity flow supply chain, we verify the effectiveness of the algorithm and the reliability of the model, this section gives an example and analyzes the example in detail.

Example 4.1. Currently, there are 2 manufacturers, 1 retailer and 1 demand market direct selling single commodity flow supply chain network, and the production cost function of the manufacturer is:

$$
f_{1}(q)=2 q_{1}^{2}+q_{1} q_{2}+2 q_{1}, \quad f_{2}(q)=2 q_{2}^{2}+q_{1} q_{2}+2 q_{2}
$$

The transaction cost function of manufacturer and corresponding retailer is:

$$
c_{11}\left(q_{11}\right)=q_{11}^{2}+3 q_{11}, \quad c_{21}\left(q_{21}\right)=q_{21}^{2}+3 q_{21} .
$$

The transaction cost function between the manufacturer and the demand market is:

$$
\mathrm{c}_{11}\left(\hat{\mathrm{q}}_{11}\right)=\hat{\mathrm{q}}_{11}^{2}+2 \hat{\mathrm{q}}_{11}, \quad \mathrm{c}_{21}\left(\hat{\mathrm{q}}_{21}\right)=\hat{\mathrm{q}}_{21}^{2}+3 \hat{\mathrm{q}}_{21} .
$$

The retailer's management cost is:

$$
c(Q)=0.5\left(q_{11}+q_{21}\right)^{2} .
$$

Let's start at $X^{0}=\left(X_{1}^{0}, \ldots, X_{7}^{0}\right)$. The results obtained by solving the equation with gradient projection algorithm are shown in the following Table 1.

Table 1: Model solution results.

\begin{tabular}{|c|c|c|c|c|c|c|}
\hline $\begin{array}{c}\text { The output } \\
\text { of }\end{array}$ & $\begin{array}{c}\text { The output } \\
\text { of } \\
\text { manufacturer } \\
1\end{array}$ & $\begin{array}{c}\text { Product } \\
\text { traffic from } \\
\text { manufacturer } \\
1 \text { to retailer }\end{array}$ & $\begin{array}{c}\text { Product } \\
\text { traffic from } \\
\text { manufacturer } \\
2 \text { to retailer }\end{array}$ & $\begin{array}{c}\text { Volume } \\
\text { flow from } \\
\text { manufacturer } \\
\text { to demand } \\
\text { market }\end{array}$ & $\begin{array}{c}\text { Volume } \\
\text { manufacturer } \\
2 \text { to demand } \\
\text { market }\end{array}$ & $\begin{array}{c}\text { Volume } \\
\text { flow from } \\
\text { to demailers } \\
\text { markets }\end{array}$ \\
\hline 61.3311 & 2 & 17.2626 & 15.7771 & 9.7948 & 9.6091 & 9.7787 \\
\hline
\end{tabular}




\section{Acknowledgment}

The authors gratefully acknowledge the valuable comments of the editor and the reviewers. This work is supported by the Shandong Province Soft Science Research Project (2012RKA13021), the Natural Science Foundation of Shandong Province (ZR2018MA016), and the college students' innovation and entrepreneurship training program (201810452083).

\section{References}

[1] X. Y. Fu, T. G. Chen, Supply Chain network optimization based on fuzzy multiobjective centralized decision-making model, Math. Probl. Eng., 2017 (2017), 11 pages. 1

[2] E. M. Gafni, D. P. Bertsekas, Two-metric projection problems and descent methods for asymmetric variational inequality problems, Math. Program., 53 (1984), 99-110. 3.1, 3

[3] Y. Malitsky, Projected reflected gradient methods for monotone variational inequalities, SIAM J. Optim., 25 (2015), 502 520. 1

[4] A. Nagurney, J. Cruz, J. Dong, D. Zhang, Supply Chain Networks, Electronic Commerce, and Supply Side and Demand Side Risk, Eur. J. Oper. Res., 164 (2005), 120-142. 1

[5] C. C. Poirier, Supply chain optimization: building the strongest total business network, Berrett-Koehler Publ., San Francisco, (1996). 1

[6] C. C. Poirier, Advanced supply chain management: how to build a sustained competitive advantage, Berrett-Koehler Publ., San Francisco, (1999).

[7] H. Stadtler, C. Kilger, Supply Chain Management and Advanced Planning, Springer-Verlag, Berlin, (2000). 1

[8] N. H. Xiu, J. Z. Zhang, Some recent advances in projection-type methods for variational inequalities, J. Comput. Appl. Math., 152 (2003), 559-585. 3, 3.4

[9] E. H. Zarantonello, Projections on Convex Sets in Hilbert Space and Spectral Theory: Part I. Projections on Convex Sets: Part II. Spectral Theory, Contribut. Nonlinear Funct. Anal., 1971 (1971), 237-424. 3

[10] L. P. Zhang, A Nonlinear Complementarity Model For Supply Chain Network Equilibrium, J. Ind. Manag. Optim., 3 (2007), 727-737. 1

[11] D. Zhang, J. Dong, A. Nagurney, A Supply Chain Network Economy: Modeling and Qualitative Analysis, in: Innovations in Financial and Economic Networks, 2003 (2003), 197-213. 1

[12] G. T. Zhang, H. Sun, J. S. Hu, G. X. Dai, The Closed-Loop supply Chain network equilibrium with products lifetime and carbon emission constraints in multiperiod planning horizon, Discrete Dyn. Nature Society, 2014 (2014), 16 pages. 1 